\title{
ANATOMÍA FOLIAR DE OCHO ESPECIES DE ORQUÍDEAS EPÍFITAS
}

\author{
Rafael Arévalo ${ }^{1,2,3}$, Juana Figueroa ${ }^{2} \&$ Santiago Madriñán $^{2}$ \\ ${ }^{1}$ Department of Botany, University of Wisconsin-Madison, 430 Lincoln Drive, Madison, WI 53706-1381, U.S.A. \\ ${ }^{2}$ Laboratorio de Botánica y Sistemática, Universidad de los Andes, Bogotá, Apartado 4976, Colombia. \\ ${ }_{3}^{3}$ Autor para correspondencia: rafarev@gmail.com
}

Resumen. Para contribuir con el conocimiento de las bases vegetativas del epifitismo en Orchidaceae, se desarrolló un estudio de las variaciones anatómicas foliares que pueden presentarse en diferentes tipos de plantas epifitas. Se escogieron cuatro especies que representaran las diferentes categorías de epífitas - epífita de humus (Oncidium abortivum Rchb.f.), epífita de corteza (Epidendrum excisum Lindl.) y epifitas de ramita (Rodriguezia lehmannii Rchb.f. e Hirtzia escobarii Dodson) - , y cuatro especies que crecieran como epífitas y como plantas terrestres-Elleanthus oliganthus (Poepp. \& Endl.) Rchb.f., Elleanthus purpureus (Rchb.f.) Rchb.f., Pleurothallis cordifolia Rchb.f. \& H.Wagener, y Stelis sp. Distintas combinaciones de caracteres xerofíticos propios de plantas adaptadas a crecer en ambientes con baja disponibilidad de recursos hídricos se evidenciaron en todas las especies: mayor desarrollo de células de la epidermis adaxial, engrosamientos de las paredes periclinales de la epidermis, tricomas glandulares, estomas con poro protegido, ocurrencia de hipodermis, haces de células esclerenquimáticas, presencia de diferentes tipos de idioblastos y células esclerenquimáticas rodeando los haces vasculares. Las epífitas de ramita, restringidas a los ejes más pequeños y expuestos de sus hospederos, presentaron varios de estos caracteres.

ABSTRACT. Leafs of representative epiphytic orchids were examined for anatomical detail. Four species representing the different epiphyte categories were selected for the study: Oncidium abortivum Rchb.f. (humus epiphyte), Epidendrum excisum Lindl. (branch epiphyte), Rodriguezia lehmannii Rchb.f., and Hirtzia escobarii Dodson(twig epiphytes). Additionally, four orchid species capable of developing as terrestrial plants and as epiphytes were also examined: Elleanthus oliganthus (Poepp. \& Endl.) Rchb.f., Elleanthus purpureus (Rchb.f.) Rchb.f. Pleurothallis cordifolia Rchb.f. \& H.Wagener, and Stelis sp. Various xerophytic characters, that could be considered leaf adaptations to water shortage in the epiphytic habit, were common for most species: greater development of adaxial epidermal cells, stomata with protected pores, occurrence of hypodermis, presence of fiber bundles, different type of idioblasts, and sclerenchyma present adjacent to the xylem and phloem. Twig epiphytes, restricted to the outermost axes of their hosts, exhibit several of these modifications.

Palabras clave / Key words: Anatomía foliar, Orchidaceae, Epifitismo, Adaptación, Leaf anatomy, Epiphytism, Adaptation.

Introducción. La familia Orchidaceae es considerada una de las familias más grandes de plantas vasculares con más de 25,000 especies distribuidas por todo el planeta (Dressler 1981, 2005). Con el 70\% de sus especies presentando una forma de vida epífita, constituyen más de dos tercios de todas las epífitas vasculares, siendo el grupo más diverso de este tipo de plantas (Atwood 1986, Kress 1986). Con el objeto de clasificar a las orquídeas epífitas, Dressler (1981) planteó tres categorías ecológicas generales: las epífitas de humus, que crecen solamente donde exista una capa de humus; las epífitas de corteza, que se adhieren con firmeza a troncos y ramas grandes; y las epífitas de ramita, plantas diminutas que se encuentran en los ejes más pequeños y expuestos de sus hospederos.

Varias modificaciones estructurales y adaptaciones fisiológicas están relacionadas con la expresión y surgimiento del epifitismo dentro de las Orchidaceae. Estas incluyen: la anatomía particular de sus raíces (presencia de exodermis y velamen); los pseudobulbos 
o engrosamientos en el tallo; la disposición, morfología y anatomía de las hojas; los patrones de crecimiento; y la ruta metabólica fotosintética conocida como metabolismo ácido de las crasulaceas-CAM, por sus siglas en inglés (Dressler 1981, Benzing \& Ott 1981, Benzing et al. 1983, Benzing \& Atwood 1984, Benzing 1989, Benzing 1990, Sinclair 1990, Silvera et al. 2009). La interacción de estos caracteres y mecanismos, en combinación con las características reproductivas únicas que presentan-como la gran cantidad de semillas diminutas adaptadas a la dispersión por viento (microspermia), la relación simbiótica con micorrizas para la germinación (micotrofía), y la estructura floral modificada para polinizadores específicos (resupinación, labelo, columna y polinaria) - , han otorgado a las orquídeas grandes oportunidades evolutivas que han facilitado su expansión y la colonización del dosel en los bosques tropicales (Benzing \& Atwood 1984, Benzing 1986, Goh \& Kluge 1989).

Se ha argumentado que la limitante abiótica más relevante para el crecimiento y funcionamiento vegetativo de las epífitas vasculares es la escasez de agua (Zotz \& Hietz 2001). La toma efectiva de agua, el almacenamiento dentro de la planta y el control de la pérdida de ésta, son factores determinantes en la expresión del epifitismo en las orquídeas (Sinclair 1990). Johansson (1975) sostuvo que el patrón de distribución espacial de las orquídeas epífitas parecía ser el resultado de la interacción entre la necesidad por captar altas intensidades lumínicas y la capacidad de tolerar la fuerza de evaporación del aire. Puesto que las hojas son el lugar principal en donde se lleva a cabo la fotosíntesis, estas deben mantener un intercambio de gases adecuado con el aire circundante, lo que conlleva una pérdida de agua inevitable. Cualquier planta sujeta a escasez de agua, debe poseer modificaciones en la morfología, anatomía y fisiología de sus hojas, y la estructura de estas, también debe reflejar la respuesta de la planta a los recursos que se encuentran a su disposición (Sinclair 1990, Garnier \& Laurent 1994, Reich et al. 1999).

Lareducción de la transpiraciónyel almacenamiento de agua, hacen parte de las estrategias que poseen las hojas para tolerar sequías. En las orquídeas, dentro los caracteres de las hojas que permiten reducir la pérdida de agua se encuentran: el grosor de la cutícula, la densidad y distribución de los estomas, la presencia de pelos superficiales y el hecho de ser deciduas (Sinclair 1990). Para el almacenamiento de agua, las hojas de algunas orquídeas poseen una hipodermis que funciona como tejido de acumulación de agua , que en algunos géneros puede llegar a ocupar hasta el $80 \%$ del volumen de la hoja (Pridgeon 1986). Dentro del tejido hipodérmico también se pueden encontrar idioblastos con paredes engrosadas que acumulan agua y evitan el colapso del tejido durante los periodos de desecación (Olatunji et al. 1980). En otros casos, las células del mesófilo se agrandan y pueden asumir una función de almacenamiento mientras retienen algunos cloroplastos (Sinclair 1990).

Con el presente trabajo se amplía el conocimiento sobre los caracteres foliares asociados con el hábito epífito, basándose en ocho especies de orquídeas que representan formas de crecimiento variado. A continuación, se describe la anatomía foliar de cuatro especies que representan a los distintos tipos ecológicos de epífitas propuestos por Dressler (1981), y cuatro especies que se encontraron creciendo como plantas terrestres y como epífitas.

Materiales y métodos. Se escogieron cuatro especies de orquídeas que representaran a cada una de las categorías de epífitas propuestas por Dressler (1981) — epífita de humus, epífita de corteza y epífita de ramita - y cuatro especies de orquídeas que crecían como plantas terrestres, enraizadas y expuestas en taludes de una carretera y como epífitas de corteza, sobre árboles dentro de un bosque húmedo de montaña (Tabla 1).

Las especies estudiadas fueron colectadas en su hábitat natural: Elleanthus oliganthus, E. purpureus, Pleurothaillis cordifolia, Stelis sp. y Rodriguezia lehmannii, en la vereda Monte Bello, municipio de Pueblo Rico, departamento de Risaralda (05'14'40" N, 760' 15" W); Oncidium abortivum y Epidendrum excisum, en un bosque húmedo de montaña de la vereda Cedeño , municipio Támesis, departamento de Antioquia (053' $53^{\prime}$ " N, 7542'13” W); e Hirtzia escobarii en cultivos de guayaba en la vereda Toriba Bajo , Municipio San Francisco, departamento de Cundinamarca $\left(04^{\circ} 37^{\prime} 0^{\prime \prime} \mathrm{N}, 74^{\circ} 48^{\prime} 0^{\prime}\right.$ ' W).

Los individuos muestreados fueron plantas adultas, en estado de floración y que no presentaban síntomas 
TABLA 1. Lista de especies de orquídeas estudiadas.

\begin{tabular}{l|l|l|l} 
Especie & Categoría de epífita & Colector y No. & Herbario \\
\hline Oncidium abortivum Rchb.f. & Epífia de humus & J. Figueroa 36 & ANDES \\
\hline Epidendrum excisum Lindl. & Epífita de corteza & J. Figueroa 14 & ANDES \\
\hline Hirtzia escobarii Dodson & Epífita de ramita & J. Figueroa 7 & ANDES \\
\hline Rodriguezia lehmannii Rchb.f. & Epífita de ramita & R. Arévalo 684 & ANDES \\
\hline Elleanthus oliganthus (Poepp. \& Endl.) Rchb.f & Epífita de corteza / terrestre & R. Arévalo 456 & ANDES \\
\hline Elleanthus purpureus (Rchb.f) Rchb.f & Epífita de corteza / terrestre & R. Arévalo 679 & ANDES \\
\hline Pleurothallis cordifolia Rchb.f. \& H.Wagener & Epífita de corteza / terrestre & R. Arévalo 482 & ANDES \\
\hline Stelis sp. & Epífita de corteza / terrestre & R. Arévalo 504 & ANDES
\end{tabular}

de ataques por parte de patógenos o herbívoros. Hojas maduras y completamente expandidas (1 hoja por planta, 5 plantas por especie) fueron almacenadas en solución fijadora $1: 1: 18$ de $40 \%$ formol, ácido acético y 70\% alcohol (70\%) (FAA) para ser llevadas al laboratorio donde se efectuaron los análisis anatómicos. A cada hoja se le hicieron cortes transversales a mano alzada y a nivel de la parte media. Se tomaron medidas del grosor de la hoja y de las cutículas ( 5 medidas por hoja, 25 por especie) usando un microscopio Nikon ${ }^{\circledR}$ Eclipse 4000 equipado con un micrómetro ocular. Los resultados fueron registrados a través de microfotografías. La presencia de elementos lignificados se detectó mediante el uso de azul de toluidina 0 (Herr 1993). Se describe la anatomía foliar de las distintas especies teniendo en cuenta múltiples observaciones (cortes) y con base en los siguientes caracteres: cutícula, células epidérmicas, estomas, haces fibrosos, hipodermis, mesófilo y haces vasculares.

\section{Resultados}

\section{EPÍFITA DE HUMUS}

Oncidium abortivum: hojas coriáceas, duras, conduplicadas, lanceoladas, $332.4 \pm 64.9 \mu \mathrm{m}$ de grosor. Cutícula adaxial $2.7 \pm 0.3 \mu \mathrm{m}$ de grosor; abaxial 1.5 $\pm 0.2 \mu \mathrm{m}$ de grosor. Células epidérmicas oblongas; las células adaxiales más grandes que las abaxiales. Estomas al mismo nivel de las células epidérmicas; cámara subestomática más grande que células del mesófilo adyacentes. Haces fibrosos abaxiales en dos series que se alternan (Fig. 1A). Hipodermis adaxial uniseriada, interrumpida por idioblastos angulares con paredes lignificadas gruesas (Fig. 1B); abaxial ausente. Mesófilo homogéneo, 10-12 células de grosor, redondas a oblongas, con paredes delgadas. Haces vasculares de diferentes tamaños, intercalados; xilema y floema rodeado por vaina vascular más gruesa hacia los polos.

\section{EPÍFITA DE CORTEZA}

Epidendrum excisum: hojas coriáceas, carnosas, conduplicadas, ovadas, $1014.0 \pm 161.62 \mu \mathrm{m}$ de grosor. Cutícula $12.7 \pm 1.68 \mu \mathrm{m}$ de grosor; $8.7 \pm 0.82$ $\mu \mathrm{m}$ de grosor. Células epidérmicas rectangulares a cuadradas, paredes celulares periclinales engrosadas (Fig. 2A). Estomas ligeramente hundidos en relación a las células epidérmicas; cámara subestomática más pequeña que células adyacentes del mesófilo; con proyecciones cuticulares (Fig. 2B). Haces fibrosos ausentes. Hipodermis adaxial 3-4 células de grosor, presencia de idioblastos con leves engrosamientos parietales en bandas irregulares (Fig. 2A); abaxial uniseriada. paredes celulares engrosadas. Mesófilo homogéneo, 13-15 células de grosor, células con grandes vacuolas (Fig. 2C); idioblastos con rafidios de gran tamaño (Fig. 2D). Haces vasculares de diferentes tamaños, intercalados; xilema y floema rodeado por vaina vascular más gruesa hacia el polo del xilema en los haces más grandes (Fig. 2C).

\section{EPIFITAS DE RAMITA}

Hirtzia escobarii: hojas coriáceas, carnosas, fuertemente conduplicadas, elípiticas, angostas, 2315.4 $\pm 196.9 \mu \mathrm{m}$ de grosor. Cutícula adaxial $5.6 \pm 0.2 \mu \mathrm{m}$ 


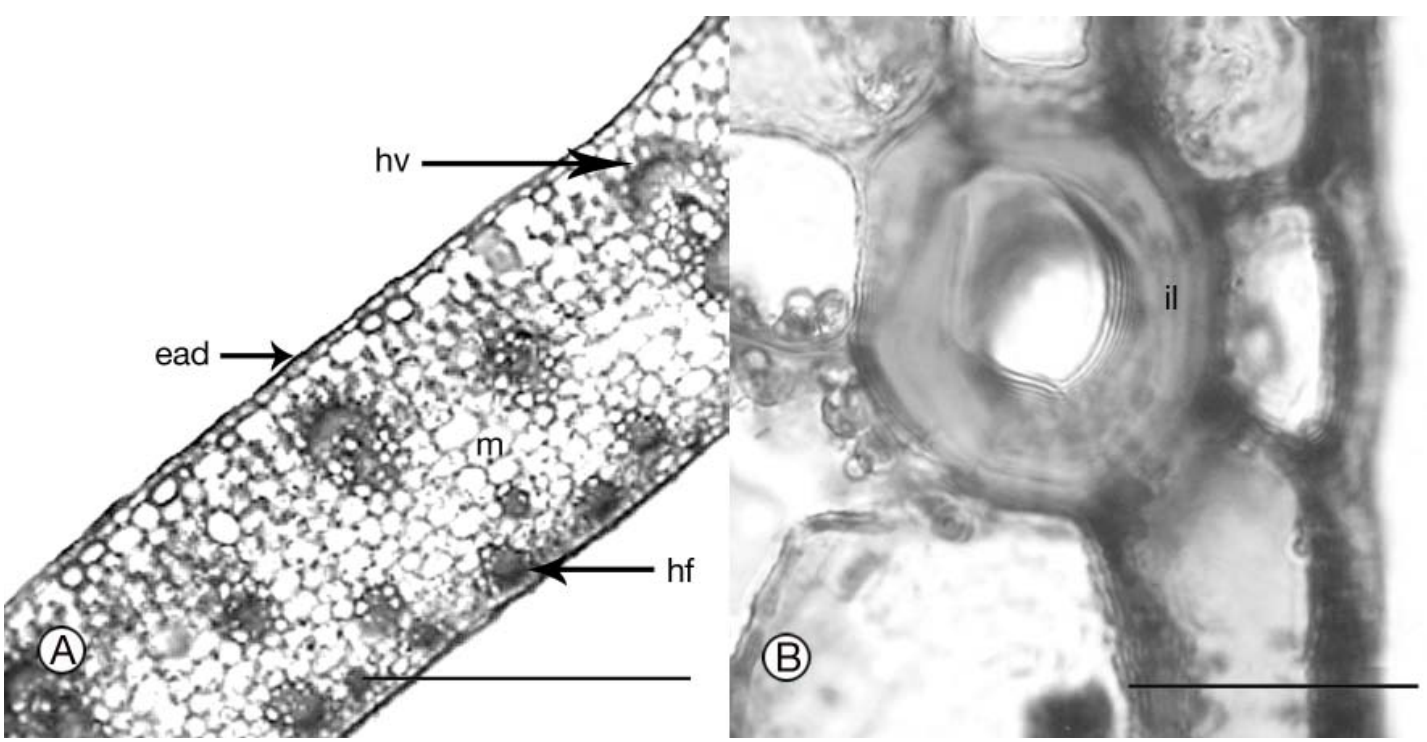

Figura 1. Oncidium abortivum: A. Aspecto general; células de la epidermis adaxial (ead) de mayor tamaño que las de la epidermis abaxial, células del mesófilo (m) redondas a oblongas, haces vasculares (hv) de varios tamaños, dos series de haces fibrosos en región abaxial (hf). B. Idioblasto angular con engrosamiento parietal lignificado (il). Escalas: $\mathrm{A}=300 \mu \mathrm{m} ; \mathrm{B}=40 \mu \mathrm{m}$.

de grosor; abaxial $3.8 \pm 0.82 \mu \mathrm{m}$ de grosor. Células epidérmicas oblongas. Estomas al mismo nivel de las demás células epidérmicas; cámara subestomática más pequeña que células adyacentes del mesófilo; proyecciones cuticulares externas presentes. Haces fibrosos compuestos por varias células con paredes lignificadas gruesas, dispuestos en una serie a nivel de la hipodermis abaxial (Fig. 3A: hf). Hipodermis adaxial uniseriada, células dipuestas anticlinalmente, de tamaño variado, con paredes lignificadas gruesas (Fig. 3B: hl); abaxial uniseriada, células isodiamétricas a oblongas, con paredes lignificadas gruesas, interrumpida por haces fibrosos (Fig. 3A). Mesófilo homogéneo, alrededor de 20 células de grosor, células isodiamétricas hacia la parte media, alargadas anticlinalmente hacia ambas superficies, células con grandes vacuolas que ocupan gran parte del volumen celular; idioblastos globosos con leves engrosamientos transversales en bandas irregulares (Fig. 3C). Haces vasculares de diferentes tamaños, intercalados; xilema y floema rodeado por vaina vascular cuyas células esclerenquimáticas presentan paredes más gruesas hacia los polos (Fig. 3D).

Rodriguezia lehmannii: hojas coriáceas, carnosas, conduplicadas y elípticas, $1570.4 \pm 265.07$ $\mu \mathrm{m}$ de grosor. Cutícula adaxial lisa, $12.3 \pm 2.67 \mu \mathrm{m}$ de grosor; abaxial ligeramente bulada, $6.0 \pm 1.01 \mu \mathrm{m}$ de grosor. Células epidérmicas oblongas, dispuestas periclinalmente, de mayor tamaño en la superficie adaxial (Fig. 4A). Estomas al mismo nivel de las demás células epidérmicas; cámara subestomática de menor tamaño que células adyacentes del mesófilo; proyecciones cuticulares externas pronunciadas formando una cámara supraestomática (Fig. 4B). Haces fibrosos compuestos por grupos de células esclerenquimáticas, en una serie y al mismo nivel de la hipodermis abaxial (Fig. 4A y C). Hipodermis adaxial uniseriada interrumpida por idioblastos elipsoidales a cilíndricos y con engrosamientos parietales helicoidales (Fig. 4D); la abaxial uniseriada, con células de paredes lignificadas gruesas intercalándose con haces fibrosos (Fig. 4C). Mesófilo relativamente homogéneo, 9-10 células de grosor, las adaxiales con más cloroplastos y todas con vacuolas grandes que ocupan gran parte del volumen celular (Fig. 4D). Haces vasculares hacia la parte media de la hoja; xilema y floema rodeado por vaina vascular cuyas células esclerenquimáticas presentan paredes celulares más gruesas hacia el polo del floema (Fig.4E). 


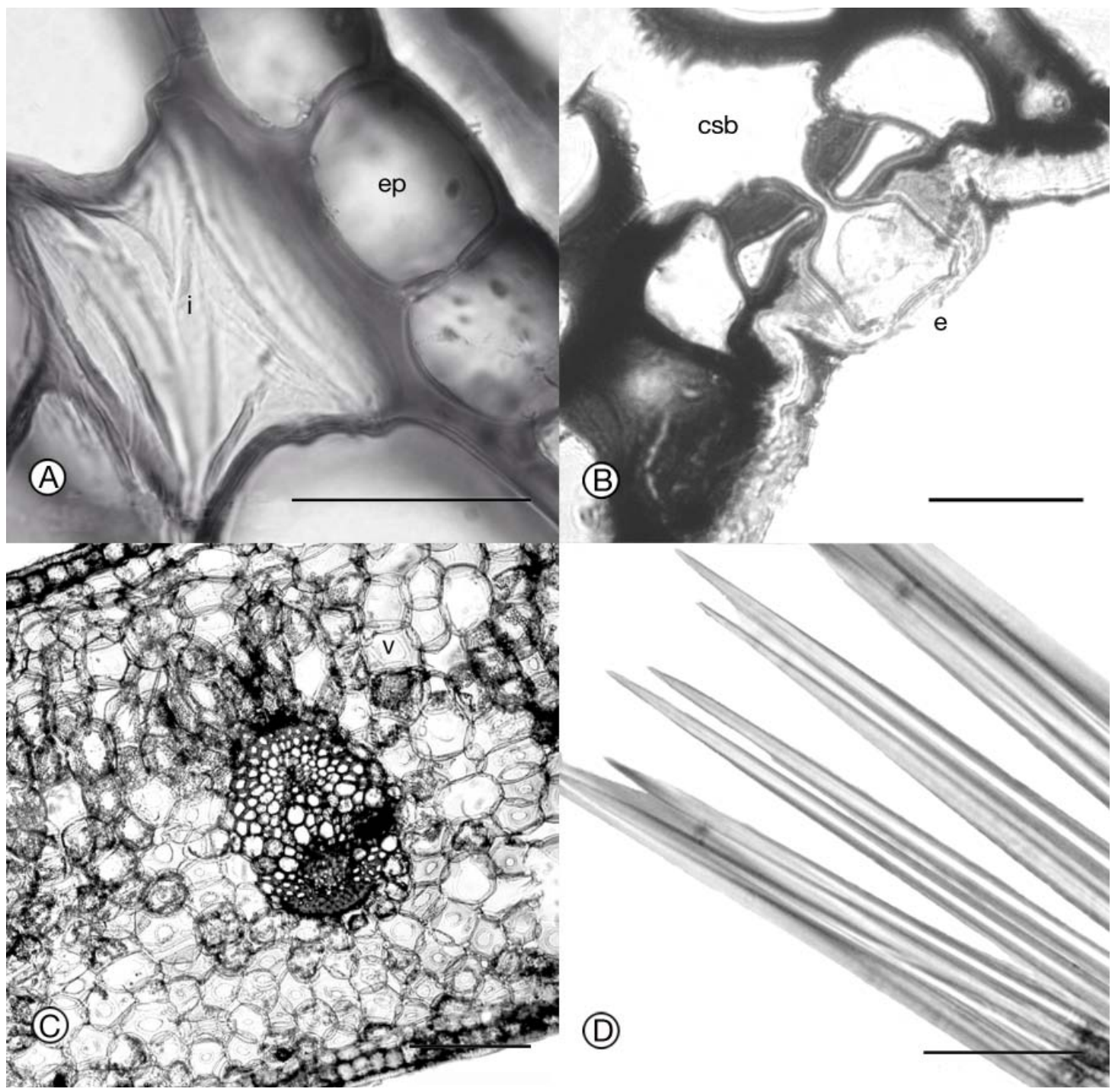

FIGURA 2. Epidendrum cf. excisum. A. Idioblasto (i) con engrosamiento parietal secundario en forma de bandas irregulares, paredes periclinales de la epidermis gruesas (ep). B. Estoma (e) con células guardia de lumen triangular y cámara subestomática (csb) de menor tamaño que células del mesófilo adyacentes. C. Aspecto general; vacuolas (v) que ocupan gran parte del volumen celular. D. Rafidios de gran tamaño. Escalas: A=10 $\mu \mathrm{m} ; \mathrm{B}, \mathrm{D}=30 \mu \mathrm{m} ; \mathrm{C}=200 \mu \mathrm{m}$.

\section{EPIFITAS Y TERRESTRES}

Elleanthus oliganthus: hojas plicadas, ovadas, $217.0 \pm 15.8 \mu \mathrm{m}$ de grosor en epífitas y $228.8 \pm$ $20.2 \mu \mathrm{m}$ de grosor en terrestres. Cutícula adaxial levemente bulada, $4.6 \pm 0.8 \mu \mathrm{m}$ de grosor en epífitas y $4.2 \pm 1.0$ en terrestres; abaxial de textura algo verrugosa - con pequeñas proyecciones granulares (Fig. 5A), $2.3 \pm 0.4 \mu \mathrm{m}$ de grosor en epífitas y $2.4 \pm$
$0.2 \mu \mathrm{m}$ de grosor en terrestres. Células epidérmicas oblongas a isodiamétricas, las adaxiales más grandes e isodiamétricas; tricomas glandulares situados en superficie abaxial (Fig. B). Estomas al mismo nivel de las demás células epidérmicas; cámara subestomática del mismo tamaño que células adyacentes del mesófilo; leves proyecciones cuticulares externas e internas (Fig. 5A, e). Haces fibrosos ausentes. Hipodermis ausente. Mesófilo relativamente homogéneo, 5-7 células de 

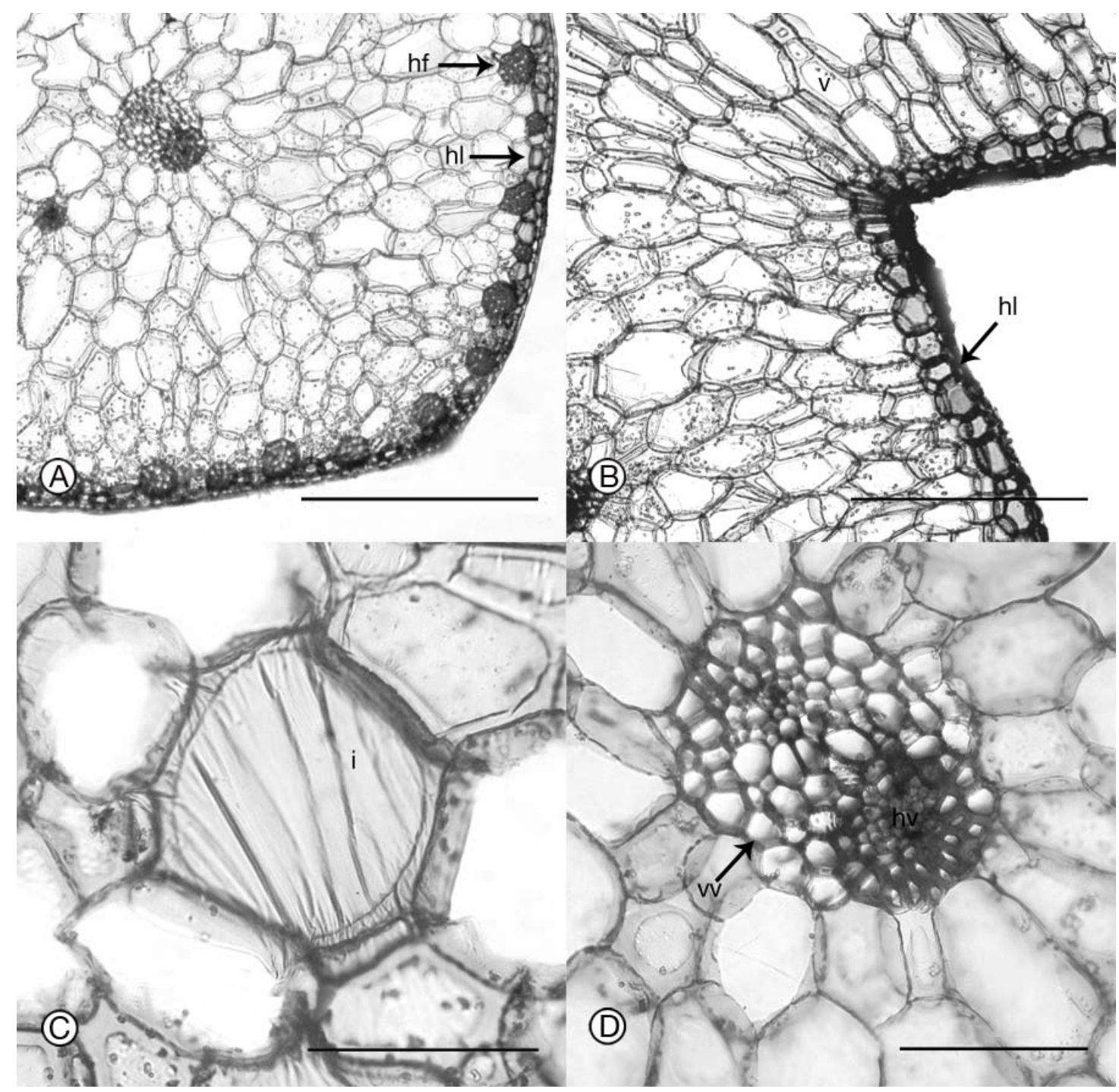

Figura 3. Hirtzia escobarii: A. Hipodermis abaxial lignificada (hl) interrumpida por haces fibrosos (hf). B. Hipodermis adaxial de células con paredes lignificadas gruesas (hl), vacuolas (v) que ocupan gran parte del volumen celular. C. Idioblasto globoso con engrosamiento parietal secundario en forma de bandas irregulares (i). D. Disposición radiada de células que rodean haz vascular (hv), xilema y floema rodeado por vaina vascular (vv). Escalas: $A, B=60 \mu \mathrm{m}, \mathrm{C}=30$ $\mu \mathrm{m} . \mathrm{D}=10 \mu \mathrm{m}$.

grosor, células oblongas; idioblastos con rafidios presentes (Fig. 5C). Haces vasculares de diferentes tamaños, haces grandes se alternan con dos tipos de haces mas pequeños; los haces grandes con el xilema y floema rodeado por vaina vascular más gruesa hacia los polos (Fig. 5D).

Elleanthus purpureus: hojas plicadas, ovadas, $175.4 \pm 9.4 \mu \mathrm{m}$ de grosor en epífitas y $255.3 \pm 14.6 \mu \mathrm{m}$ de grosor. Cutícula adaxial lisa a ligeramente bulada a lo largo del contorno de las células epidérmicas, $4.5 \pm 0.4 \mu \mathrm{m}$ de grosor en epífitas y $7.0 \pm 0.9 \mu \mathrm{m}$ de grosor en terrestres; abaxial finamente bulada a lo largo del contorno de las células epidérmicas, $1.9 \pm 0.3 \mu \mathrm{m}$ de grosor en epífitas y $3.7 \pm 0.5 \mu \mathrm{m}$ de grosor en terrestres (Fig. 6A). Células epidérmicas isodiamétricas a oblongas; tricomas glandulares situados en depresiones epidérmicas presentes en 


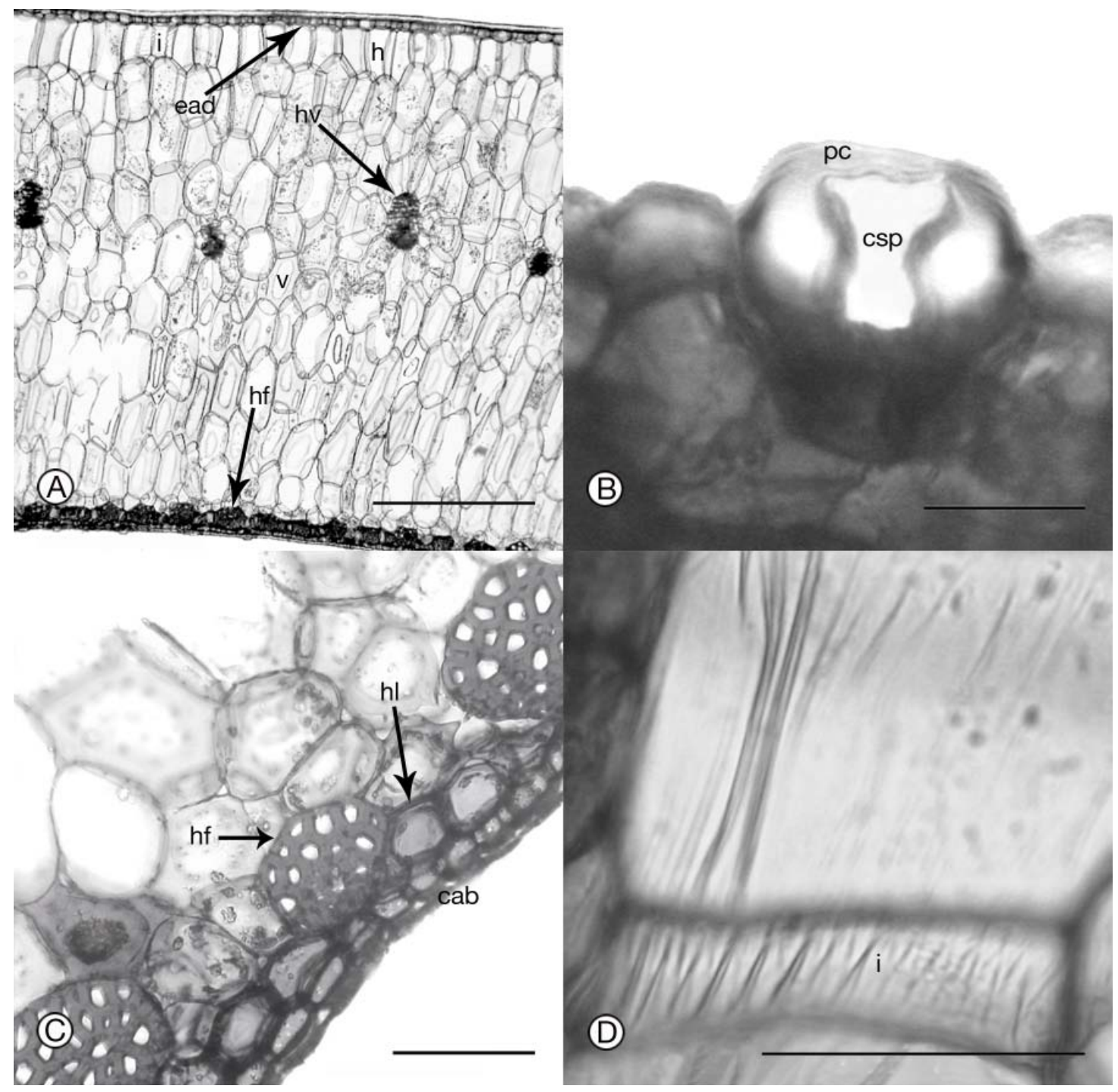

Figura 4. Rodriguezia lehmannii: A. Aspecto general; células de la epidermis adaxial (ead) de mayor tamaño que las de la epidermis abaxial, hipodermis adaxial (h) constituida por idioblastos (i) con engrosamientos parietales helicoidales, células del mesófilo con vacuolas que ocupan gran parte del volumen celular (v), haces vasculares (hv) grandes y pequeños. B. Estoma (e) con proyecciones cuticulares (pc) pronunciadas y cámara supraestomática (csp) alargada. C. Hipodermis abaxial lignificada (hl) interrumpida por haces fibrosos (hf). D. Idioblasto (i) elipsoidal con engrosamiento parietal secundario helicoidal. E. Haz vascular (x y f) rodeado por vaina vascular (vv), cuyas células esclerenquimáticas presentan paredes celulares más gruesas hacia el polo del floema (f). Escalas: A,B,C=30 $\mu \mathrm{m} ; \mathrm{D}=400 \mu \mathrm{m} ; \mathrm{E}=40 \mu \mathrm{m}$.

ambas superficies (Fig. 6B). Estomas al mismo nivel de las demás células epidérmicas; cámara subestomática de igual o mayor tamaño que células adyacentes del mesófilo; proyecciones cuticulares externas presentes (Fig. 6A). Haces fibrosos ausentes. Hipodermis ausente. Mesófilo heterogéneo, 7-10 células de grosor, las células abaxiales, dispuestas periclinalmente, oblongas a isodiamétricas, con espacios intercelulares conspicuos (parénquima esponjoso); las adaxiales en dos series de células isiodiamétricas (parénquima empalizada) (Fig. 6C); idioblastos con rafidios e idioblastos mucílaginosos presentes. Haces vasculares de diferentes tamaños, haces grandes se alternan con dos tipos de haces 


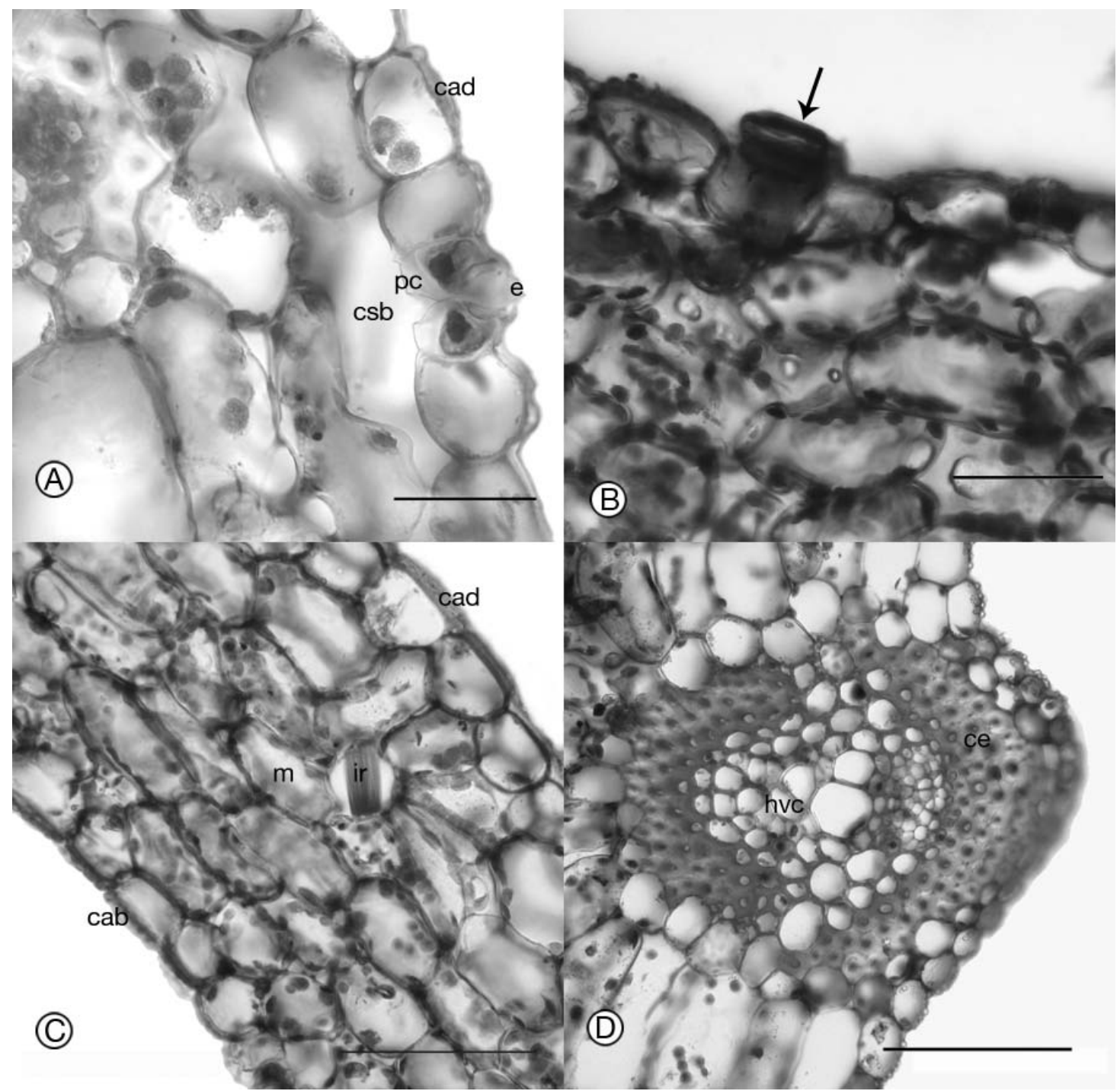

Figura 5. Elleanthus oliganthus. A. Estoma (e) con células guardia de lumen triangular y cámara subestomática. (csb) de igual tamaño a células del mesófilo adyacentes, leves proyecciones cuticulares. internas (pc). B. Tricoma glandular de la superficial abaxial de la hoja. C. Aspecto general; cutícula adaxial levemente abollada (cad), cutícula abaxial abollada de textura verrugosa (cab), células del mesófilo oblongas dispuestas periclinalmente (m), idioblasto con rafidios (ir). C. Haz vascular central (hvc), células de esclerénquima (ce) concentradas hacia los polos del floema y del xilema. Escalas: $\mathrm{A}=30 \mu \mathrm{m} ; \mathrm{B}=50 \mu \mathrm{m} ; \mathrm{C}=100 \mu \mathrm{m} ; \mathrm{D}=200 \mu \mathrm{m}$.

más pequeños; xilema y floema rodeado por vaina vascular más gruesa hacía los polos.

Pleurothallis cordifolia: hojas coriáceas, algo carnosas, fuertemente cordadas, $838.7 \pm 75.6 \mu \mathrm{m}$ de grosor en epífitas y $942.1 \pm 71.3 \mu \mathrm{m}$ de grosor en terrestres. Cutícula adaxial lisa, $7.9 \pm 0.7 \mu \mathrm{m}$ de grosor en epífitas y $7.9 \pm 1.4 \mu \mathrm{m}$ de grosor en terrestres; abaxial lisa, $2.1 \pm 0.2 \mu \mathrm{m}$ de grosor en epífitas y 2.6 $\pm 0.4 \mu \mathrm{m}$ de grosor en terrestres. Células epidérmicas oblongas a rectangulares; tricomas glandulares situados en depresiones epidérmicas presentes en ambas superficies (Fig. 7A). Estomas al mismo nivel de las demás células epidérmicas; cámara subestomática de mayor o igual tamaño que células adyacentes del mesófilo (Fig. 7B). Haces fibrosos ausentes. 


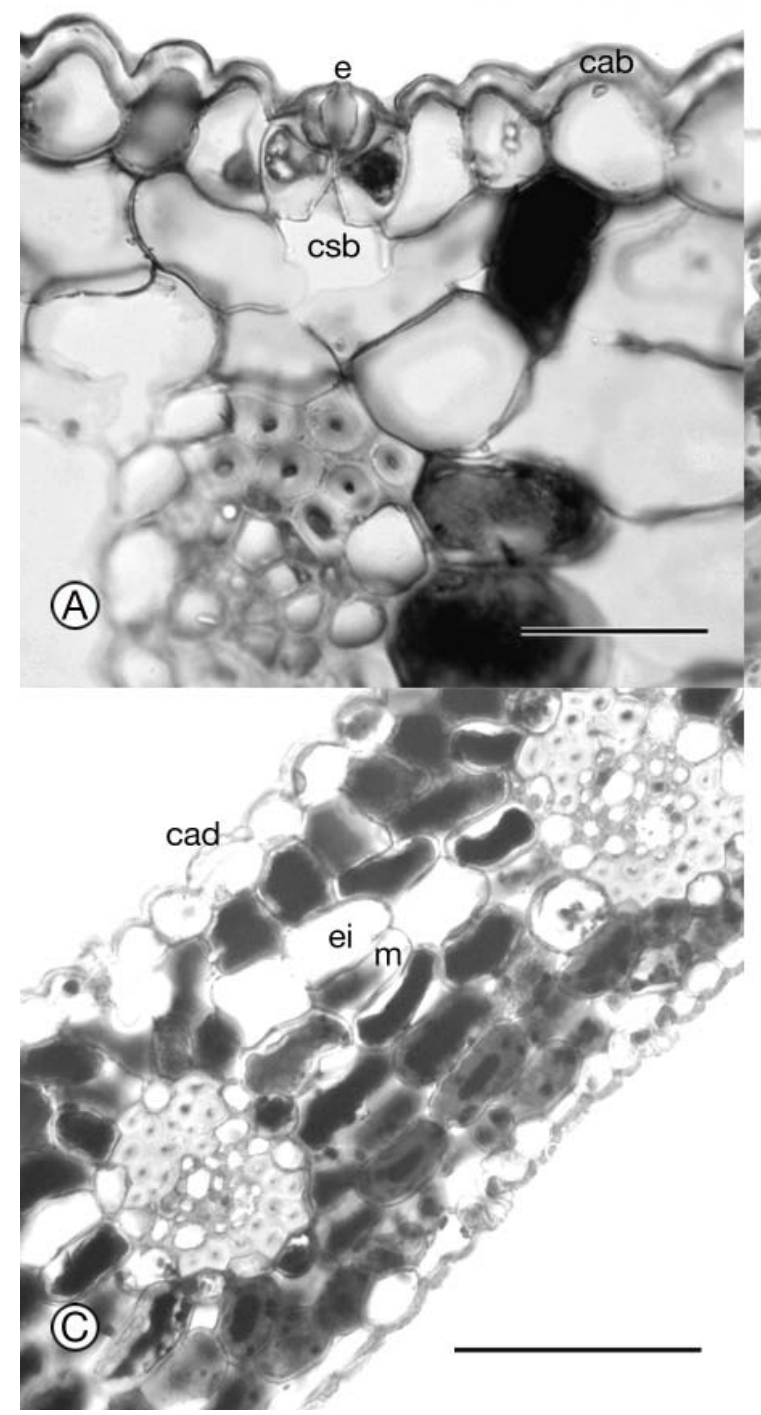

Hipodermis adaxial compuesta por dos series, células con engrosamientos parietales helicoidales; abaxial uniseriada, células con engrosamientos parietales helicoidales. Mesófilo heterogéneo, 8-10 células de grosor; el parénquima esponjoso compuesto por células oblongas a isodiamétricas; grandes idioblastos ovoides, con engrosamientos helicoidales e idioblastos con rafídios (Fig. 7C y D); el parénquima empalizada compuesto por dos series, una serie de células columnares, y otra de células oblongas a isodiamétricas (Fig. 7E); en algunas células del mesófilo se presentan pequeñas gotas amarillas de aceite. Haces vasculares de diferentes tamaños, distribuidos en una serie ubicada
FigurA 6. Elleanthus purpureus. A. Cutícula abaxial finamente abollada (cab), estoma (e) con proyecciones cuticulares curvas y cámara subestomática (csb) de menor tamaño que células del mesófilo adyacentes. B. Tricoma glandular (tg). C. Aspecto general; cutícula adaxial lisa a ligeramente abollada (cad), células del mesófilo $(\mathrm{m})$ oblongas a isodiamétricas con espacios intracelulares conspicuos (ei). Escalas: $\mathrm{A}=30 \mu \mathrm{m} ; \mathrm{B}=50$ $\mu \mathrm{m} ; \mathrm{C}=300 \mu \mathrm{m}$.

entre el mesófilo de empalizada y el esponjoso: xilema y floema rodeado por vaina vascular; una serie de células esclerenquimáticas separa el xilema del floema.

Stelis sp.: hojas coriáceas, carnosas, ovadas, 661.3 $\pm 60.5 \mu \mathrm{m}$ de grosor en epífitas y $814.0 \pm 121.7 \mu \mathrm{m}$ de grosor en terrestres. Cutícula adaxial lisa, $4.6 \pm$ $0.4 \mu \mathrm{m}$ de grosor en epífitas y $7.2 \pm 2.1 \mu \mathrm{m}$ de grosor en terrestres; abaxial lisa $2.0 \pm 0.1 \mu \mathrm{m}$ de grosor en epífitas y $2.8 \pm 0.9 \mu \mathrm{m}$ de grosor en terrestres. Células epidérmicas dispuestas periclinalmente y oblongas a rectangulares, las adaxiales más grandes; tricomas glandulares en depresiones epidérmicas presentes en 

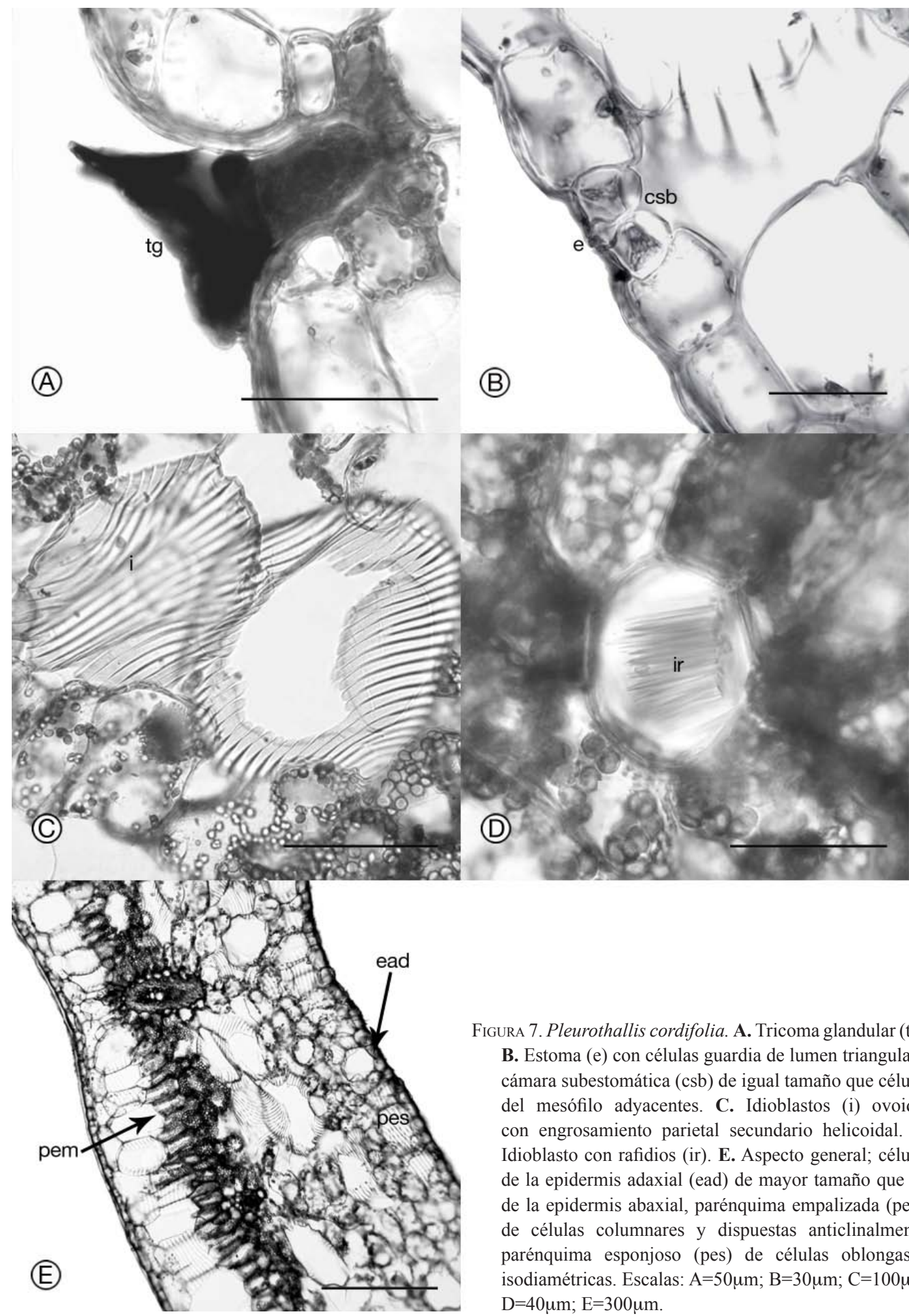

Figura 7. Pleurothallis cordifolia. A. Tricoma glandular (tg). B. Estoma (e) con células guardia de lumen triangular y cámara subestomática (csb) de igual tamaño que células del mesófilo adyacentes. C. Idioblastos (i) ovoides con engrosamiento parietal secundario helicoidal. D. Idioblasto con rafidios (ir). E. Aspecto general; células de la epidermis adaxial (ead) de mayor tamaño que las de la epidermis abaxial, parénquima empalizada (pem) de células columnares y dispuestas anticlinalmente, parénquima esponjoso (pes) de células oblongas a isodiamétricas. Escalas: $\mathrm{A}=50 \mu \mathrm{m} ; \mathrm{B}=30 \mu \mathrm{m} ; \mathrm{C}=100 \mu \mathrm{m}$; $\mathrm{D}=40 \mu \mathrm{m} ; \mathrm{E}=300 \mu \mathrm{m}$. 


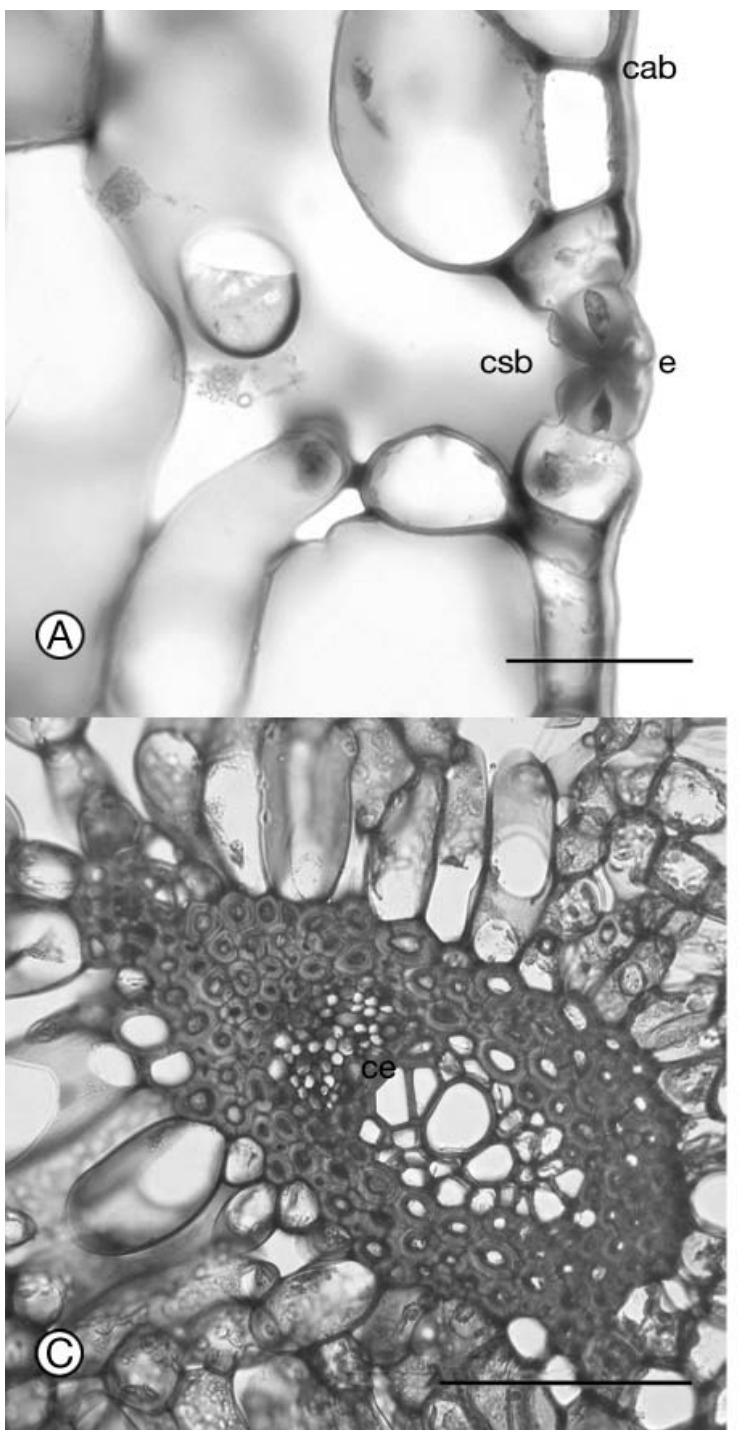

ambas caras y más abundantes en la superficie abaxial (no se muestran). Estomas al mismo nivel de las demás células epidérmicas; cámara subestomática de mayor tamaño que células adyacentes del mesófilo; pequeñas proyecciones cuticulares externas presentes (Fig. 8A). Haces fibrosos ausentes. Hipodermis adaxial 2-4 células de grosor, isodiamétricas; abaxial uniseriada. Mesófilo heterogéneo, 12-15 células de grosor; el parénquima esponjoso más grueso, compuesto por células oblongas a isiodiamértricas y dispuestas periclinalmente, espacios intercelulares conspicuos; el parénquima empalizada compuesto por 1-2 series adaxiales de células columnares y otra serie abaxial de

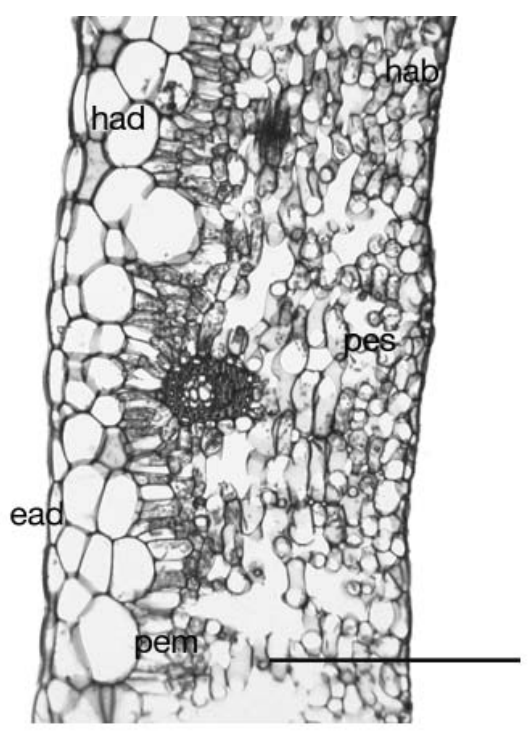

Figura 8. Stelis sp. A. Cutícula abaxial lisa (cab), estoma (e) con células guardia de lumen triangular y cámara subestomática (csb) de mayor tamaño que células adyacentes del mesófilo. B. Aspecto general; células de la epidermis adaxial (ead) de mayor tamaño que las de la epidermis abaxial, parénquima empalizada (pem) de células columnares dispuestas anticlinalmente, parénquima esponjoso (pes) de células oblongas a isodiamétricas, hipodermis adaxial (had) de 2 a 3 capas de células, hipodermis abaxial (hab) uniseriada. C. Haz vascular con serie de células esclerenquimáticas (ce) separando el xilema del floema. Escalas: $A=30 \mu \mathrm{m}$, $\mathrm{B}=400 \mu \mathrm{m}, \mathrm{C}=10 \mu \mathrm{m}$.

células oblongas a isodiámétricas (Fig. 8B); presencia de idioblastos elongados con engrosamientos parietales helicoidales (no mostrados). Haces vasculares de varios tamaños, distribuidos en una serie; los más grandes ubicados entre los dos tipos de mesófilo y los más pequeños abaxiales; esclerénquima ocurre en forma de vainas vasculares conspicuas y completas; una serie de células esclerenquimáticas separa el xilema del floema (Fig. 8C).

Resumen. En las especies estudiadas se presentaron los dos tipos de hojas que se pueden encontrar en las orquídeas (sensu Withner et al. 1974), plicadas y 
coriáceas. Todas las especies se diferenciaron en cuanto al grosor de sus hojas y las más delgadas fueron las hojas plicadas de las dos especies de Elleanthus. Entre las especies con hojas coriáceas, las dos epífitas de ramita (Hirtzia escobarii y Rodriguezia lehmannii) presentaron las hojas más gruesas, mientras la epífita de humus (Oncidium abortivum) presentó las hojas más delgadas. En cuanto al grosor de la cutícula, en todas las especies se encontró que la cutícula adaxial era más gruesa que la cutícula abaxial. Al igual que en otros representantes de la familia (Ayensu \& Williams 1972, Mohana-Rao \& Khasim 1987, Stern et al. 1993, Kurzweil et al. 1995), las hojas de O. abortivum, E. purpureus, R. lehmannii, Pleurothallis cordifolia y Stelis sp., presentaron una epidermis adaxial con células más grandes que las de la epidermis abaxial (Tabla 2). Tricomas glandulares fueron evidenciados tanto en las hojas coriáceas de las especies de Pleurothallis, como en las hojas plicadas de ambas especies de Elleanthus, aunque en E. oliganthus se observaron únicamente a nivel de la superficie abaxial (Tabla 2). Todas las especies estudiadas presentaron hojas hipoestomáticas y con los estomas al mismo nivel de las demás células epidérmicas (o ligeramente hundidos como Epidendrum excisum). En algunas especies estudiadas se observaron pequeñas proyecciones cuticulares curvas sobre las células guardia, similares a las que ya han sido descritas en otras especies de orquídeas (Ferreira 1992, Leiria 1997). La epífita de ramita, $R$. lehmannii, presentó proyecciones cuticulares externas pronunciadas, formando una cámara externa bastante alargada (Fig. 4B).

La hipodermis, considerada una de las características más comunes en plantas de crecimiento epifito, se evidenció en todas las especies de hojas coriáceas, pero de manera distinta (Tabla 2). Constituida por células de mayor tamaño que las de la epidermis, se presentó adaxial y abaxialmente, exceptuando a la epífita de humus (Oncidium abortivum), donde solo ocurrió adaxialmente (Fig. 1A). En epifitas de corteza como Epidendrum excisum y Stelis sp. se observó una hipodermis adaxial de varias series, con algunas células de paredes gruesas en E. excisum (Fig. 2A). En las epífitas de ramita (Hirtzia escobarii y Rodriguezia lehmannii), además de presentar hipodermis uniseriadas, gruesas y lignificadas, la hipodermis abaxial se ve interrumpida, en intervalos mas o menos regulares, por haces fibrosos (Fig. 4C). Estos haces también fueron observados a nivel del mesófilo en la epifita de humus O. abortivum (Fig. 1A).

Se presentaron especies con hojas de mesófilo homogéneoy especies con hojas demesófilo heterogéneo. En aquellas especies con mesófilo heterogéneo (Pleurothallis cordifolia, Stelis sp. y Elleanthus purpureus), el mesófilo se diferencia claramente en parénquima de empalizada y parénquima esponjoso. En las especies en las que el mesófilo es relativamente homogéneo (E. oliganthus y Rodriguezia lehmannii), se observan variaciones en el tamaño y forma de las células, así como en la cantidad de cloroplastos, sin embargo no existe una clara diferenciación en dos tipos de parénquima. En el mesófilo de la epífita de corteza Epidendrum excisum, y de las epifitas de ramita, Hirtzia escobarii y Rodriguezia lehmannii, predominan células con vacuolas bastante grandes que ocupan la mayor parte del volumen celular (Fig. 3A y 4D). Además, estas especies presentan espacios intercelulares reducidos, donde las cámaras subestomáticas son de menor tamaño que las células adyacentes del mesófilo (Fig. 2B).

Se encontraron diferentes tipos de idioblastosglobosos en Hirtzia escobarii, elipsoidales a cilíndricos en Rodriguezia lehmannii, angulares en Oncidium abortivum, elongados en Stelis sp. y ovoides en Pleutothallis cordifolia-, con distintos tipos de engrosamiento parietal-irregulares en Epidendrum excisum e H. escobarii y helicoidales en $R$. lehmannii, P. cordifolia y Stelis sp. En las epífitas de corteza, E. excisum, Elleanthus oliganthus, E. purpureus y $P$. cordifolia, se presentaron idioblastos con rafidios de oxalato de calcio (Fig. 2D, 5B, y 7D), corroborando descripciones anteriores sobre otros representantes de la familia (Metcalfe 1963; Wattendorff 1976; Franceschi \& Horner; Kauschik 1982; Pridgeon 1982; Campos Leite \& Oliveira 1987; Ferreira 1992; Widholzer 1993; Leiria 1997; Godoy \& Costa 2003).

En todas las especies los haces vasculares son colaterales y presentan células esclerenquimáticas que los envuelven parcial o totalmente. De acuerdo a la especie, estas células esclerenquimáticas que conforman la vaina vascular pueden estar más concentradas hacia los polos y/o variar en el grosor de sus paredes. En las dos especies de Elleanthus, en Oncidium abortivum y en Epidendrum excisum, la vaina vascular es mucho más gruesa hacia los polos del xilema y el floema que hacia la parte media. En 
TABLA 2. Caracteres morfológicos y anatómicos presentes en ocho especies de orquídeas epífitas. $+=$ presente; $-=$ ausente.

\begin{tabular}{|c|c|c|c|c|}
\hline \multirow{3}{*}{ Especie } & \multirow{3}{*}{ Pseudobulbos } & \multicolumn{3}{|c|}{$\begin{array}{l}\text { Caracteres foliares relacionados con almacenamiento de agua } \\
\qquad \text { y resistencia a desecación }\end{array}$} \\
\hline & & \multicolumn{2}{|c|}{ Epidermis } & \multirow[b]{2}{*}{ Mesófilo } \\
\hline & & Celulas epidérmicas & $\begin{array}{c}\text { Tricomas } \\
\text { glandulares }\end{array}$ & \\
\hline Elleanthus oliganthus & - & & + & \\
\hline Elleanthus purpureus & - & $\begin{array}{l}\text { adaxiales más } \\
\text { desarrolladas }\end{array}$ & $\begin{array}{c}+ \\
(\text { abaxial) }\end{array}$ & \\
\hline Epidendrum excisum & - & & - & hipodermis, idioblastos \\
\hline Hirtzia escobarii & + & & - & $\begin{array}{l}\text { hipodermis lignificada, idioblastos, } \\
\text { haces fibrosos }\end{array}$ \\
\hline Oncidium abortivum & + & $\begin{array}{l}\text { adaxiales más } \\
\text { desarrolladas }\end{array}$ & - & $\begin{array}{l}\text { hipodermis, idioblastos, haces } \\
\text { fibrosos }\end{array}$ \\
\hline Pleurothallis cordifolia & - & & + & hipodermis, idioblastos \\
\hline Stelis sp. & - & $\begin{array}{l}\text { adaxiales más } \\
\text { desarrolladas }\end{array}$ & + & hipodermis, idioblastos \\
\hline $\begin{array}{l}\text { Rodriguezia } \\
\text { lehmannii }\end{array}$ & + & $\begin{array}{l}\text { adaxiales más } \\
\text { desarrolladas }\end{array}$ & - & $\begin{array}{l}\text { hipodermis lignificada, idioblastos, } \\
\text { haces fibrosos }\end{array}$ \\
\hline
\end{tabular}

las epífitas de ramita Hirtzia escobarii y Rodriguezia lehmannii, las células esclerenquimáticas se encuentran mas concentradas hacia el polo del xilema y las células que se encuentran hacia el polo contrario del floema presentan paredes más gruesas (Fig 3D y 4E).

Cabe resaltar, que dentro de las especies estudiadas que no presentaron pseudobulbos se pueden evidenciar dos tendencias. En las especies de Pleurothallis cordifolia, Stelis sp. y Epidendrum excisum, la ausencia de engrosamientos a nivel del tallo se ve contrarrestada por el desarrollo de hojas suculentas con hipodermis adaxial y abaxial, además de la presencia de células con engrosamiento parietal secundario (Tabla 2). Por su parte, en las especies de Elleanthus la ausencia de pseudobulbos se ve acompañada por hojas delgadas que no presentan tejido de almacenamiento de agua, ni células esclerenquimáticas (Tabla 2).

Discusión. En este estudio se pudo evidenciar como especies más expuestas a los rayos solares presentan hojas y cutículas más gruesas, como el caso de la epífitas de ramita (Rodriguezia lehmannii y Hirtzia escobarii). De la misma manera, individuos terrestres de las especies de Elleanthus purpureus, Pleurothallis cordifoila y Stelis sp., que se encontraban expuestos en los taludes de la carretera, presentaron hojas y cutículas significativamente más gruesas (R. Arévalo, unpubl. data). Según Kurzweil et al. (1995), las células epidérmicas de mayor tamaño pueden estar relacionadas con la función de reserva de agua (Oliveira \& Sajo 1999), especialmente en aquellas hojas que no poseen tejidos de almacenamiento, como es el caso de E. purpureus. Se ha demostrado que los tricomas glandulares en especies de Pleurothallis no están involucrados en procesos de toma de agua y nutrientes por parte de la hoja (Benzing \& Pridgeon 1983). Sin embargo, la función de estas estructuras podría consistir en la secreción de mucílago, que actuaría reduciendo la transpiración (Pridgeon 1982), o contribuyendo con la absorción de agua (Raciborski 1898), y de cierta manera compensando la ausencia de tallos engrosados/pseudobulbos. 
Puesto que en Orchidaceae los estomas raramente ocurren hundidos (Rasmussen 1987), estos suelen exhibir otros caracteres xeromórficos. A menudo los estomas se encuentran rodeados por proyecciones cuticulares externas que forman una cámara supraestomática que protege contra la pérdida excesiva de agua y gases (Eames \& MacDaniels 1925, Metcalfe 1963, Machado \& Barros 1995). Estas cámaras supraestomáticas mantienen un compartimiento de aire húmedo que permite reducir la transpiración y son comunes en orquídeas epifitas que enfrentan altas temperaturas y poca disponibilidad de agua (Rosso 1966, Rasmussen 1987), como el caso de la epífita de ramita Rodriguezia lehmannii.

Los grupos de células esclerenquimáticas, o haces fibrosos, confieren resistencia mecánica a las hojas en casos de deshidratación y suelen presentarse en las hojas de orquídeas especializadas a sobrevivir en hábitats xerofíticos (Withner et al. 1974). Por consiguiente, era de esperarse la presencia de estos haces en las epífitas de ramita, aunque también fueron observados a nivel del mesófilo en la epifita de humus Oncidium abortivum (Tabla 2).

La abundancia de células del mesófilo con vacuolas bastante grandes que ocupan la mayor parte del volumen celular en la epífita de corteza Epidendrum excisum y en las de ramita (Rodriguezia lehmannii y Hirtzia escobarii), se presenta junto con espacios intercelulares reducidos, donde las cámaras subestomáticas son de menor tamaño que las células adyacentes del mesófilo. Éstas características foliares suelen estar asociadas a plantas con metabolismo CAM (Nelson et al. 2005). La presencia de idioblastos en el mesófilo estaría relacionada con la retención de agua y/o el soporte mecánico, evitando el colapso celular durante la desecación (Pridgeon 1982). Adicionalmente, se ha argumentado que los idioblastos con rafidios, que se hayaron en las epífitas de corteza (excepto Stelis sp.), pueden estar relacionados con el balance iónico y osmoregulación de la planta (Bonates 1993).

El engrosamiento en las paredes de las células esclerenquimáticas que conforman la vaina vascular podría conferirle mayor resistencia mecánica a las hojas en casos de deshidratación. La presencia de estos engrosamientos estaría relacionada entonces con la menor disponibilidad de agua que existe en un hábito epífito extremo, como el que se presenta en los ejes más pequeños y expuestos de los árboles hospederoslas ramitas.

El análisis de las hojas estudiadas indica la presencia de caracteres que pueden ser interpretados como adaptaciones a la economía de agua. En cada una de las plantas estudiadas se presenta una particular combinación de estos, aunque no se evidencia una clara diferenciación en la anatomía de las plantas según la categoría ecológica a la que pertenecen. Sin embargo, las epifitas de ramita se diferencian de las demás al presentar una hipodermis lignificada y varios de los caracteres propios de plantas adaptadas a crecer en ambientes con baja disponibilidad de recursos hídricos: (1) hojas y cutículas bastante gruesas; (2) estomas con cámaras supraestomáticas (en el caso de Rodriguezia lehmannii); (3) haces fibrosos; (4) hipodermis abaxial y adaxial; (5) células con grandes vacuolas; (6) vainas vasculares gruesas; y (7) teniendo en cuenta las características celulares del mesófilo, muy probablemente metabolismo CAM. Estas características deben facilitarles la colonización de la zona más expuesta a alta luminosidad y con mayor fluctuación en la disponibilidad de agua que puede encontrarse en un árbol hospederolas ramitas. Los resultados encontrados apoyan la idea que estas plantas constituyen un ejemplo de extrema modificación morfológica y fisiológica al epifitsimo.

Agradecimientos. Al Parque Nacional Natural Tatamá (Unidad Administrativa Especial del Sistema de Parques Nacionales Naturales), a su director H. Ballesteros y a todos sus funcionarios, por el apoyo logístico prestado. A los asistentes en el trabajo de campo y de laboratorio durante las distintas etapas del proyecto: A. Tapasco, O. Velez, E. Cárdenas, S. Cournier, y E Realpe, J. Agudelo y J. Betancur. A P. Ortíz por su colaboración en la identificación de especies; y a L. Nieto por su asesoría en la edición de las imágenes. A los revisores anónimos por la lectura crítica del manuscrito. Este trabajo fue parcialmente financiado por la Fundación para la Promoción de la Investigación y la Tecnología del Banco de la República (Proyecto No. 2053), y el programa Proyectos Semilla del Comité de Investigaciones y Posgrados de la Facultad de Ciencias de la Universidad de los Andes. A los revisores anónimos por la lectura crítica del manuscrito y sus sugerencias para esta versión final. 


\section{LITERATURA CITADA}

Atwood, J.T. 1986. The size of the Orchidaceae and the systematic distribution of epiphytic orchids. Selbyana 9: 171-186.

Ayensu, E.S. \& N.H. Williams. 1972. Leaf anatomy of Palumbina and Odontoglossum, subgenus Osmoglossum. Amer. Orchid Soc. Bull. 41: 687-696.

Benzing, D.H. \& A.M. Pridgeon. 1983. Foliar trichomes of Pleurothallidinae (Orchidaceae): Functional significance. Amer. J. Bot. 70(2): 173-180.

Benzing, D.H. \& D.W. Ott. 1981. Vegetative reduction in epiphytic Bromeliaceae and Orchidaceae: Its Origin and significance. Biotropica 13: 131-140.

Benzing, D.H. \& J.T. Atwood. 1984. Orchidaceae: ancestral habitats and current status in forest canopies. Syst. Bot. 9: $155-165$.

Benzing, D.H. 1986. The genesis of orchid diversity: emphasis on floral biology leads to misconceptions. Lindleyana 1(2): 73-89.

Benzing, D.H. 1989. The evolution of epiphytism. Vol. 76, Pp. 15-40 en: U. Lüttge (ed.), Vascular plants as epiphytes: evolution and ecophysiology. SpringerVerlag, Berlin.

Benzing, D.H. 1990. Vascular epiphytes. Cambridge University Press, Cambridge.

Benzing, D.H., W.E. Friedman, G. Peterson \& A. Renfrow. 1983. Shootlessness, velamentous roots, and the preeminence of Orchidaceae in the epiphytic biotope. Amer. J. Bot. 70(1): 121-133.

Bonates, L.C.M. 1993. Estudos ecofisiológicos de Orchidaceae da Amazonia II - Anatomia ecológica foliar de espécies com metabolismo CAM de uma campina da Amazônia Central. Acta Amazonica 23(4): 315-348.

Campos Leite, V.M. \& P.L. Oliveira. 1987. Morfoanaomia foliar de Cattleya intermedia (Orchidaceae). Napaea 2: $1-10$.

Dressler, R.L. 1981. The orchids: Natural History and Classification. Harvard University Press, Cambridge.

Dressler, R.L. 2005. How many orchid species? Selbyana 26(1): 155-158.

Eames, A.J. \& L.H. MacDaniels. 1925. An introduction to plant anatomy. McGraw-Hill Book Company Inc, Nueva York.

Ferreira, J.L.B. 1992. Anatomia foliar de espécies da subtribo Pleurohallidinae (Orchidaceae). Tesis de Maestría. Universidade Federal do Rio Grande do Sul, Porto Alegre.

Franceschi, V.R. \& H.T. Horner Jr. 1980. Calcium oxalate crystals in plants. Bot. Rev. 46: 361-427.

Garnier E. \& G. Laurent. 1994. Leaf anatomy, specific mass and water content in congeneric annual and perennial grass species. New Phytol. 128: 725-736.

Godoy, R. \& C. Costa. 2003. Anatomia foliar de quarto espécies do gênero Cattleya Lindl. (Orchidaceae) do Planalto Central Brasileiro. Acta Bot. Brasil. 17(1): 101-118.

Goh C.J. \& M. Kluge 1989. Gas exchange and water relations in epiphytic orchids. Cap. 6, Pp. 139-163 en: L. Ulrich (ed), Vascular Plants as epiphytes, Evolution and ecophysiology. Springer-Verlag, Berlin.

Herr, J.M. 1993. Clearing techniques for the study of vascular plant tissues in whole structures and thick sections. Vol. 5, Pp. 63-84 en: C.A. Goldman, P.L. Hauta, M.A. O'Donnell, S.E. Andrew and R. Vna der Heiden (eds), Tested studies for laboratory teaching. Proceedings of the 5th Workshop/Conference of the Association for Biology Laboratory Education (ABLE).

Johansson, D.A. 1975. Ecology of epiphytic orchids in west African rain forest. Amer. Orchid Soc. Bull. 44: 125-136.

Kauschik, P. 1982. Anatomy of Aerides (Orchidaceae) and its ecological and taxonomical bearing. Phytomorphology 40: $157-166$.

Kress, W.J. 1986. The systematic distribution of vascular epiphytes: an update. Selbyana 9: 2-22.

Kurzweil, H., H.P. Linder, W.L. Stern \& A.M. Pridgeon. 1995. Comparative vegetative anatomy and classification of Diseae (Orchidaceae). Bot. J. Linn. Soc. 117: 171-220.

Leiria, D.P.S. 1997. Anatomia foliar das especies nativas do gênero Oncidium Sw., Seção Synsepala (Orchidaceae) ocorrentes no morro Santana (POA) - RS. Tesis de Maestría. Universidade Federal do Rio Grande do Sul, Porto Alegre.

Machado, R.D. \& C.F. Barros. 1995. Epidermis and epicuticular waxes of Syagrus coronata leaflets. Canad. J. Bot. 73: 1947-1952.

Metcalfe, C. 1963. Comparative Anatomy as a Modern Botanical Discipline. Vol. 1. Advance in Botanical Research. Academic Press, Londres y Nueva York.

Mohana-Rao, P.R. \& S.M. Khasim. 1987. Anatomy of three species of Bulbophyllum (Orchidaceae) with comments on their ecological adaptability and taxonomy. Proc. Indian Acad. of Sci. P1. Sci. 97: 391-397.

Nelson, E.A., T.L. Sage \& R.F. Sage. 2005. Functional leaf anatomy of plants with crassulacean acid metabolism. Funct. Plant Biol. 32: 409-419.

Olaunji, O.A. \& R.O. Nengim. 1980. Ocurrence and distribution of tracheoidal elements in the Orchidaceae. Bot. J. Linn. Soc. 80: 357-370.

Oliveira, V.D.C \& M.D.G. Sajo. 1999. Anatomia foliar de especies epifitas de Orchidaceae. Revista Brasil. Bot. 22(3): 365-374.

Pridgeon, A.M. 1981. Absorbing trichomes in the 
Pleurothallidinae (Orchidaceae). Amer. J. Bot. 68(1): 64-71.

Pridgeon, A.M. 1982. Diagnostic anatomical characters in the Pleurothallidinae (Orchidaceae). Amer. J. Bot. 69(6): 921-938.

Pridgeon, A.M. 1986. Anatomical adaptations in Orchidaceae. Lindleyana 1: 90-101.

Raciborski, M. 1898. Biologische Mittheilungen aus Java. Flora 85: 325-361.

Rasmussen, H. 1987. Orchid stomata structure, differentiation, funtion, and phylogeny. Vol. IV, Pp. 105-138 en: J. Arditti (ed), Orchid biology: reviews and perspectives. Cornell Universiy Press, Nueva York,

Reich P.B., D.S. Ellsworth, M.B. Walters, J.M. Vose, C. Gresham, J.C. Volin \& W.D. Bowman. 1999. Generality of leaf trait relationships: a test across six biomes. Ecology 80(6): 1955-1969.

Rosso, S.W. 1966. The vegetative anatomy of the Cypripedioideae (Orchidaceae). Bot. J. Linn. Soc. 59: 309-341

Sinclair, R. 1990. Water relations in orchids. Vol. V, Pp.
63-120 en: J. Arditti (ed.), Orchid biology-reviews and perspectives. Timber Press, Portland, Oregon.

Stern, W.L., M.W. Morris, W.S. Judd, A.M. Pridgeon \& R.L. Dressler. 1993. Comparative vegetative anatomy and systematics of Spiranthoideae (Orchidaceae). Bot. J. Linn. Soc. 113: 161-197.

Wattendof, J.A. 1976. Third type of raphide crystal in the plant kingdom: Six-sided raphides with laminated sheaths in Agave americana L. Planta 130: 303-311.

Widholzer, C.F. 1993. Morfo-anatomia foliar de espécies do gênero Sophronites Ldl. (Orchidaceae) ocorrentes o Rio Grande do Sul, Brasil. Dissertação de Mestrado. Universidade Federal do Rio Grande do Sul, Porto Alegre.

Withner, C.L., P.K. Nelson, \& P.J. Wejksnora. 1974. The anatomy of orchids. Pp. 267-334 en: C.L. Withner (ed), The Orchids: scientific studies. John Wiley, Nueva York,

Zotz G, V. Thomas \& W. Hartung. 2001. Ecophysiological consequences of differences in plant size: abscisic acid relationships in the epiphytic orchid Dimerandra emarginata. Oecologia 129:179-185. 